\title{
Future changes in precipitation, evapotranspiration and streamflows in the Mono Basin of West Africa
}

\author{
Lamboni Batablinlè ${ }^{1}$, Lawin E. Agnidé ${ }^{2}$, Kodja Domiho Japhet ${ }^{3}$, Amoussou Ernest ${ }^{3}$, and Vissin Expédit ${ }^{3}$ \\ ${ }^{1}$ Institute of Mathematics and Physical Sciences, University of Abomey-Calavi, BP 613 Porto-Novo, Benin \\ ${ }^{2}$ Applied Hydrology Laboratory, University of Abomey-Calavi, BP 4521 Cotonou, Benin \\ ${ }^{3}$ Laboratory Pierre Pagney, Climate, Water, Ecosystems and Development, \\ University of Abomey-Calavi, BP 4521 Cotonou, Benin \\ Correspondence: Lamboni Batablinlè (lbata1982@yahoo.fr) \\ Published: 16 November 2021
}

\begin{abstract}
The impact of climate change on precipitation and water availability is of major concern for policy makers in the Mono Basin of West Africa, whose economy mainly depends on rainfed agriculture and hydropower generation. The objective of this study is to project rainfall, flows and evapotranspiration (ET) in the future period and understand their changes across Mono River Basin. Observed data were considered for the historical period 1980-2010, and a Multi-model ensemble for future projections data of eight selected Regional Climate Models under RCP 4.5 and RCP 8.5 over the periods 2011-2100 was used. The GR4J model was used to simulate daily flows of the Mono watershed. The ensemble mean shows a decrease and increase streamflows between $-54 \%$ and $42 \%,-58 \%$ and $31 \%$ under the RCP4.5, RCP8.5 scenario, respectively. The greatest decreases of high flows is projected to occur in the near term under RCP8.5, whereas the greatest decrease of low flows is projected to occur in the long term under the same RCP. For the rainfall and ET, the both scenarios (RCP4.5 and RCP8.5) predict an increase of ET while the rainfall will decrease. The results of this study of would be very useful in the choice of management and adaptation policies for water resources management.
\end{abstract}

\section{Introduction}

The future projection of climate change reported by the 5th Intergovernmental Panel on Climate Change (IPCC) assessment indicated that the global mean temperature will continue to rise for the rest of 21th century, and the amplitude for 2081-2100, relative to 1986-2005 ranges from 0.3 to $4.8^{\circ} \mathrm{C}$, under four Representative Concentration Pathways (RCP) scenarios (IPCC, 2007). An increase in temperature results in a higher evapotranspiration (ET) demand and will, in combination with a decrease in precipitation, severely stress the water resources in the region. In particular, all of Africa is highly likely to experience warming during this century, with the warming expected to exceed the global average (IPCC, 2007). Climate change and increasing climate variability might add to these trends and further degrade the availability and quality of water and arable land (Giertz and Diekkrüger, 2003). However, the spatiotemporal behaviour of precipitation, river discharge, ET, minimum and maximum temperature depend on the regional and local forcing.

The impact of climate change on precipitation and water availability is of major concern for policy makers in the Mono Basin of West Africa. In order to proffer solutions to the problems associated with water resources management within the Mono, there is a need to understand the relationship between these variables at the basin's scale.

The aim of this work is to project the rainfall, flows and ET in the future period and understand their changes.

\section{Study area location, Data used and Methodological Approach}

\subsection{Study area location}

This study area has already been described by certain authors (Batablinlè et al., 2018; Ernest et al., 2014). The Mono river basin is in West Africa and extends over $560 \mathrm{~km}$ from 


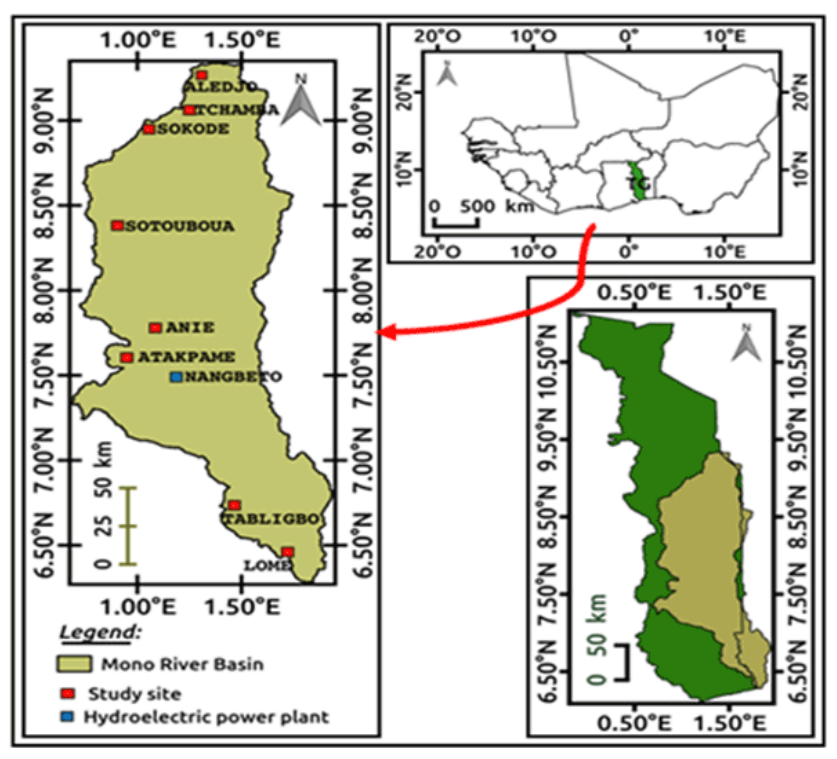

Figure 1. Study area location and considered stations (sources Batablinlè et al., 2018).

the north to the south. This transboundary watershed covers $15680 \mathrm{~km}^{2}$ and is shared by Benin and Togo. Mono basin is located more precisely between $06^{\circ} 16^{\prime} \mathrm{N}$ and $09^{\circ} 20^{\prime} \mathrm{N}$ and $0^{\circ} 42^{\prime} \mathrm{E}$ and $20^{\circ} 25^{\prime} \mathrm{E}$. This watershed is home to the Nangbéto hydroelectric dam that has been providing electricity to Benin and Togo since September 1987.

Within the West African context, rainfall in the study area is characterized by two types of Rainfall regimes In southern basin, (from $6^{\circ} 16$ to $7^{\circ} 30 \mathrm{~N}$ ) there are two rainy seasons which to mid-July and from mid-August to October. In northern basin (from $7^{\circ} 30$ to $9^{\circ} 20 \mathrm{~N}$ ), there is one rainy season which extends from April to October. The population of the basin is more than two million, with an annual increase of $2.9 \%$. This population also distributed at high densities in the south of the basin has as main activities, agriculture (mainly rain fed); in the lower valleys, fishing and salt-farming are the major activities (Ernest et al., 2014). The study area is presented in Fig. 1 below.

\subsection{Data used and Methodological Approach}

Two sources of data have been used in this paper. The first one is CORDEX program. Models data have been bias corrected by Batablinlè et al. (2018). In this study, multi-model's ensemble only will be considered. The last source of data is the observed data provided by the National Meteorology Agency of Togo for the period 1960-2010 for some stations spatially located as shown by Fig. 1. The ET of the current and future climate was calculated. In order to estimate ETo considering only temperature measurements, we used the Hargreaves-Samani equation (Hargreaves and Samini, 1985).
GR is a family of lumped hydrological models designed for flow simulation at various time steps. The models are now available in a flexible two main R-packages called airGR. The GR4J model has been extensively tested in a large number of watersheds in France, Australia, Brazil (Perrin et al., 2001). It has been used in a context of climatic variability in the Upper Ouémé basin (Ague et al., 2014). The GR4J model was used to simulate daily flow of the Mono watershed. The model parameters were calibrated and validated on a daily scale with respect to the hydro-meteorological inputs observed from 1971 to 1987 and from 1988 to 2010, respectively. These sub-periods are homogeneous and belong to the dry or wet sequence obtained after the analysis of the stationarity break in the rainfall and flow chronicles. Statistical analyses produced Nash-Sutcliffe efficiencies (NSEs) of 0.76 and 0.61 for model calibration and validation, respectively, which were considered acceptable.

The changes from the reference period are assessed as shown by Eq. (1) for ET, rainfall or flow :

$I_{p}=\left(\frac{\mathrm{FF}-\mathrm{HIST}}{\mathrm{HIST}}\right) \times 100$

Where FF and HIST represent respectively the mean for the far future (2011-2100) and the historical or reference period (1981-2010).

Sensitivity analysis is used to determine the influence of two main climatic variables on future flows. The daily average variables used in this study are: Future precipitation and evapotranspiration (ET). Flows sensitivity to climate variables was estimated by varying each variable individually, leaving the other variables constant.

A sensitivity coefficient (Eq. 2) was calculated to determine the degree of influence of each climate variable on the flow:

$S_{\mathrm{Vi}}=\frac{\partial Q}{\partial \mathrm{Vi}} \frac{\mathrm{Vi}}{Q}$

where $S_{\mathrm{Vi}}$ is the sensitivity coefficient, $\partial Q$ is the variation of the future flows $(Q)$ caused by the change of a variable $\partial \mathrm{Vi}$, $\mathrm{Vi}$ is the considered variable. A positive (negative) sensitivity coefficient indicates that the variable increases (decreases) the future flows. The higher the absolute value of the sensitivity coefficient is, the more the variable has influence on flows (Li et al., 2018).

The free software $\mathrm{R}$ was used to compute all the statistical parameters such as the seasonal averages as well as the annual averages and all plots presented.

\section{Results et discussions}

\subsection{Results}

\subsubsection{Projected changes in ET and the rainfall}

The changes relating to the evapotranspiration (ET) and rainfall between the future and the historical period are shown in 
Fig. 2. Under the RCP4.5 scenario, an increase in ET is projected by the mean-models that can fluctuate from $20 \%$ to $45 \%$ on average in some areas in the south. This projection varies from $5 \%$ to $38 \%$ northward and from $5 \%$ to $10 \%$ in the basin center. On this same projection period and under the scenario RCP8.5, the mean-model also predicts also a strong increase in ET the southward of the basin ranging from $10 \%$ to $45 \%$ against $3 \%$ to $40 \%$ and $5 \%$ to $15 \%$ the northward and the center, respectively (Fig. 2 to the left). If we consider the seasonal change (over the same projection period), under the RCP8.5 scenario, the mean-models predicts a decrease in rainfall from $-15 \%$ to $-41 \%$ on average excepted July, August and September (15\%), while it projected an increase in ET under the same scenario with $38 \%$ (mean value). Over the same projection period, the scenario RCP4.5 predicts a sharp decrease in rainfall on average from $-15 \%$ to $-40 \%$. The analysis of the ET shows an increase in the basin Mono excepted April, May and June (-14\%) (Fig. 2 to the right).

\subsubsection{Changes in seasonal flows}

The changes relating to the streamflows between the future and the historical period are calculated. Regarding the results of relative changes for monthly streamflows (figure is not represented), the lowest decrease is $-54.3 \%$ for the time period 2071-2100 (the far future) and is projected in the month of much while the highest increase is $42.4 \%$ and is projected in the month of December for the time period 2011-2041 (the near future) under RCP4.5. Under RCP8.5 the lowest decrease is $-58.3 \%$ and is projected in the month of April for the time period 2041-2070 while the highest increase is $39.1 \%$ and is projected in the month of September under RCP8.5 for the time period 2011-2040. In summary, mean models used have announced in general, a decrease of the streamflows over Mono basin.

Figure 3 depicts relative changes of Annual and seasonal streamflows (the near future and the far future were considered). Regarding these results, the streamflows (MAM and JJA) for the time period 2011-2040 (the near future) will increase between $2 \%$ and $50.3 \%$ under the RCP4.5 scenario and $12 \%$ and $55 \%$ under the RCP8.5 scenario while the streamflows (DJF, SON and An) will decrease between $10 \%$ and $49 \%$ under the RCP 4.5 scenario and between $4 \%$ and $56 \%$ under the RCP8.5 scenario, respectively. In summary, mean models used have announced in general, a decrease of the streamflows over Mono basin (Fig. 3) for the time period 2071-2100 (the far future) for the both scenarios. Monthly streamflows characteristics reflect the monthly changes in rainfall characteristics: A shift towards the rainy season (particularly, Murch to July) and a decrease in the dry months (particularly, November to April) are observed for all climate scenarios in Mono basin.

\subsubsection{Changes in extreme flows}

Figure 4 (to the right) presents the low $(\mathrm{Q} 95)$ and high $(\mathrm{Q} 05)$ flows magnitudes for the baseline period and the percent change in the future. The Q95 and Q05 here were computed based on the streamflows mean for the multi model ensemble. The relative mean changes of high flow (Q5), low flows (Q95) under two RCPs in the future are presented in Fig. 4. Simulations using the RCP4.5 scenario indicate more moderate changes to streamflows (Q5 and Q95), whereas the RCP8.5 climate scenarios project larger changes. Under both RCPs, decreases in general of Q5, and Q95, are projected in all three future sub periods $(\mathrm{A}=2051-2080, \mathrm{~B}=2061-2090$ and $C=2071-2100$ ), but the distribution of decreasing median values is generally wider under RCP8.5 than RCP4.5 in the middle and long terms. Furthermore, the distribution of Q95 values in the near term is much larger under RCP4.5 than under RCP8.5. The greatest decreases of Q5 is projected to occur in the near term under RCP8.5, whereas the greatest decrease of Q95 is projected to occur in the long term under the same RCP.

Figure 4 (to the left) shows the relationship between future flows and two main climatic variables. The results show that future rainfall will have a positive influence on future flows. Indeed, the increase of this variable leads to an increase in futures flows. On the other hand, an increase in future evapotranspiration leads to a decrease in future flows. For example, at annual scale, an increase of $0 \%$ to $30 \%$ of the rainfall leads to an increase in flows from 1 to $5 \mathrm{~m}^{3} / \mathrm{s}$. Conversely, increasing the evapotranspiration from $0 \%$ to $28 \%$ favors a decrease in flows from -3.5 to $-1.5 \mathrm{~m}^{3} / \mathrm{s}$ under RCP8.5. Under RCP4.5, a decrease from $-22 \%$ to $0 \%$ of the rainfall leads to a decrease in flows from -3.5 to $0 \mathrm{~m}^{3} / \mathrm{s}$.

\subsection{Discussions}

The ET and rainfall are an important climate variables that directs the change in flows. Evapotranspiration is the highest outgoing water flux in the hydrological cycle and is of vital importance in assessing the effects of climate change in water availability. Allen et al. (1998) show, Evapotranspiration changes, on their own or in combination with rainfall changes, can contribute to changes in hydrological indices such as mean monthly river flows. Our study predicts an increase of ET while the rainfall will decrease over Mono basin. Simulations of future streamflows in the Mono River project lowest increases and highest decreases of streamflows.

This can have a negative effect on future water availability in the area. the energy use is also dependent on water resources, and the availability and reliability of renewable sources are function of climate conditions, which can vary according to global climate changes. A possible and expressive loss in electricity production capacity could bring serious social and economic risks to the country. It was also 
(a)

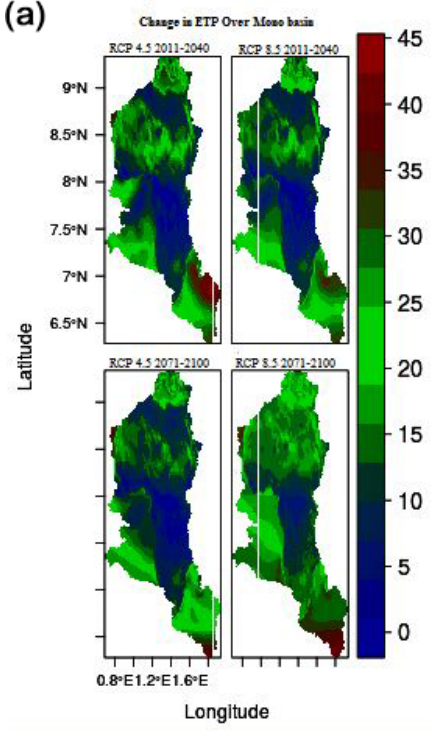

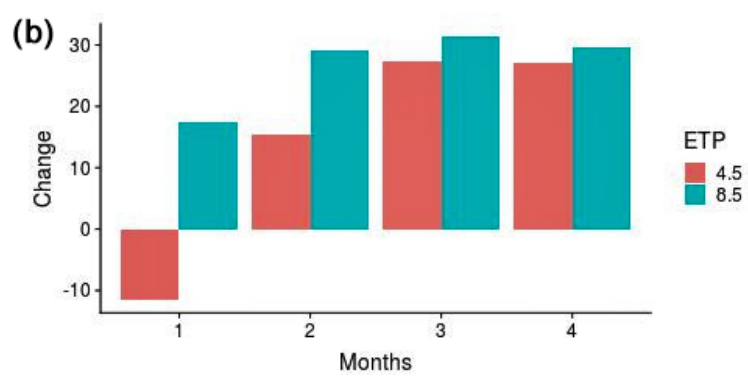

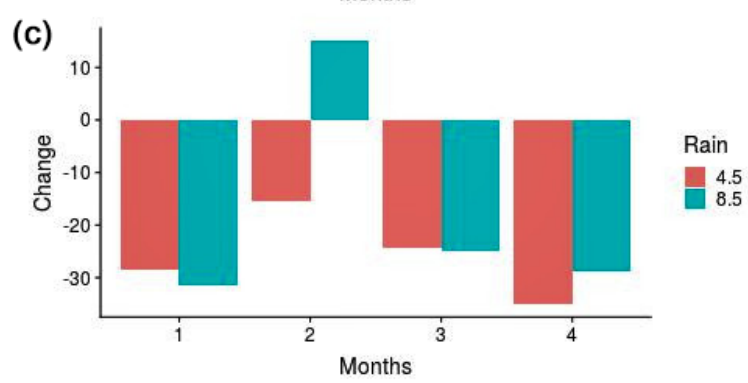

Figure 2. Spatial projected changes in ET (to the left, panel a) projected changes average ET and rainfall for each calendar month from the reference period (1981-2010) to (2011-2100); (1: April, May, June; 2: July, August, September; 3: October, November, December; 4: January, February, March), (to the right, panels b and c).
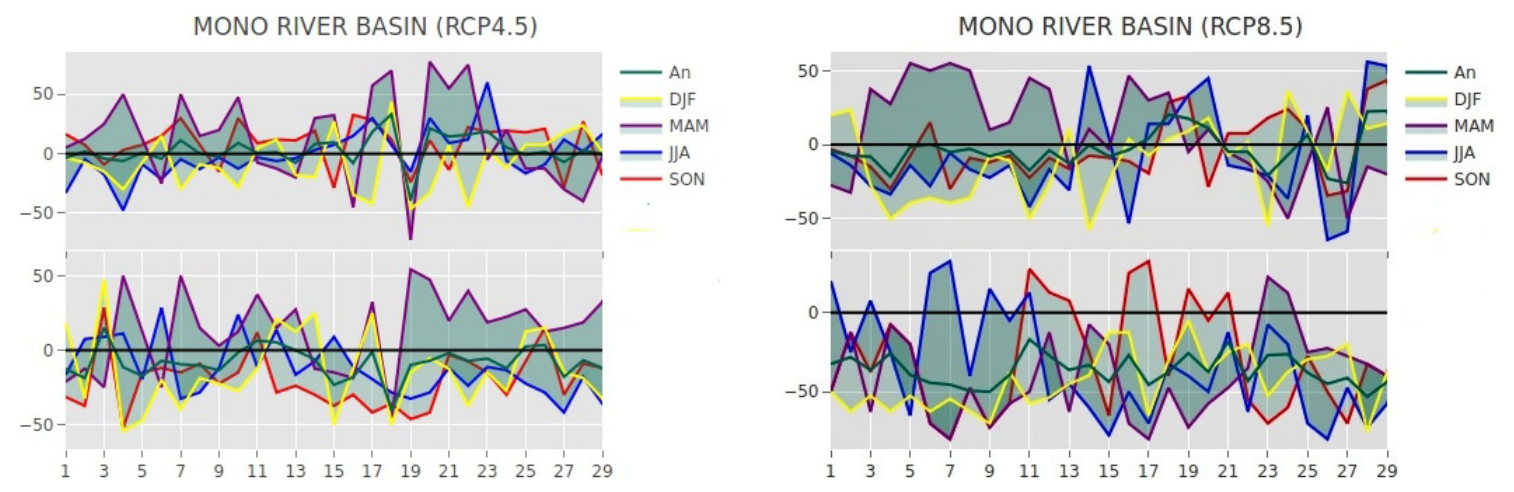

Figure 3. Annual and seasonal changes in streamflows between the futures (2011-2040 in top and 2071-2100 in below) and the historical period (1981-2010) for the average multi-models forced by RCP4.5 and RCP8.5 greenhouse gas scenarios in Mono Basin.

observed that the impact of rainfall reduction in flow production in the Mono Basin will be accentuated. Similar to previous studies in other region, results showed that the evapotranspiration is in?uenced, to a large extent, by precipitation (Liu et al., 2008). Morocco and Algeria appear to show an increase in ETref and a decrease in precipitation for future periods, meaning that water stress will become an even more severe problem in these countries in the future (TERINK et al., 2013). Jung et al. (2010) also found that the deficit of available water resources would lead to a negative global land surface evapotranspiration trend. Furthermore, a significant decrease in water availability (surface water and groundwater) due to a decrease in rainfall showed by Giertz and Diekkrüger (2003) will exacerbate following the scenario RCP8.5. Our work shows that such a change diagnosed on the present climate is likely to persist of more and more in the future. The decrease of the rainfall in the Mono basin appears to be consistent with the evolution of the ETP because a sharp increase in ETP could favor a decrease in the rainfall.

\section{Conclusion}

This study evaluated changes in climatic variables including precipitation, flows and evaporation due to climate change over the Mono basin in west Africa in the future periods (2011-2100) using regional climate models under middle and highest emission scenarios (i.e., RCP4.5 and RCP8.5). The rainfall, flows and evaporation over the historical period 1980-2010 have been analyzed at seasonal scales and interannual scales. The key findings of this study are summarized below: 

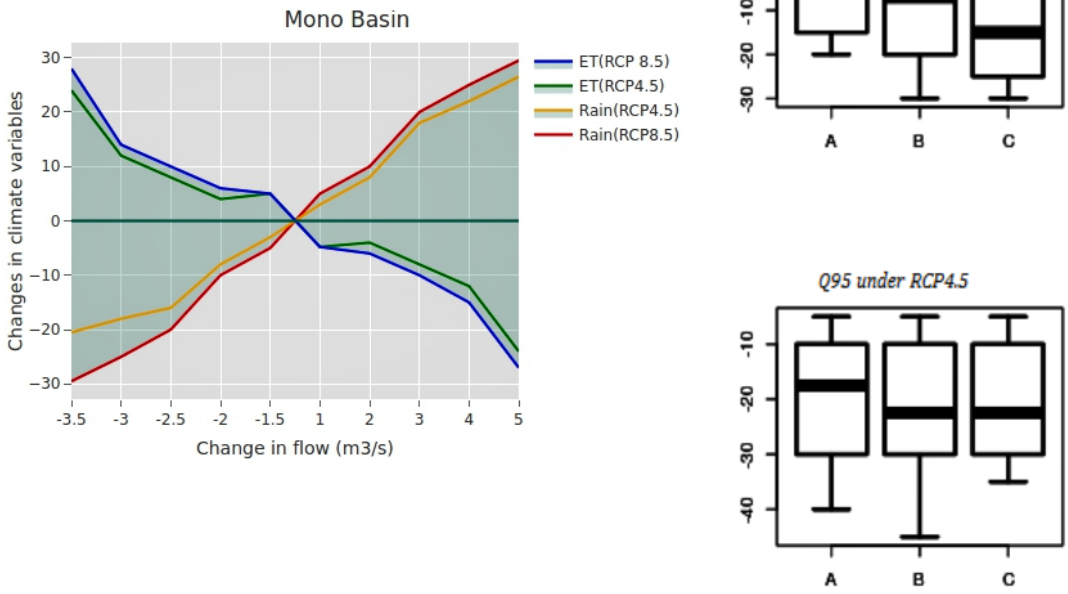
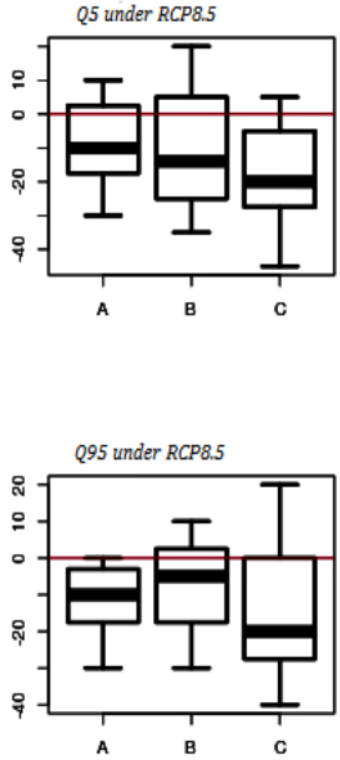

Figure 4. The relative mean changes of Q5 and Q95 under two RCPs (RCP4.5 and RCP8.5) in the future (A=2051-2080, B = 2061-2090, $\mathrm{C}=$ 2071-2100). The changes from the reference period are assessed as shown by equation for Q5 and Q95 (to the right) and the sensitivity of flows to main Climatic Variables (to the left).

1. Compared to the base period, Simulations of future streamflows in the Mono River project lowest increases and highest decreases of streamflows. It predict an increase of ET while the rainfall will decrease.

2. The results of the Sensitivity of flows to climatic variables shows that there will be impacts on water availability from climate change, reducing the streamflows in the studied area.

3. These results can serve as a basis for the implementation of prevention and water resource management strategies in the Mono catchment.

Code availability. The software $\mathrm{R}$ is freely available (http://www. gnu.org/copyleft/gpl.html, GNU Operating System, 2021). The code used in this study is not publicly accessible. Please contact the authors if you are interested in this research code.

Data availability. All data can be accessed via the references: Models data have been used in this study. It is a set of eight climatic models outputs with daily time step and spatial resolution of $0.44^{\circ}$ and available at: https://esgf-data.dkrz.de/projects/esgf-dkrz/ (DKRZ, 2017). The observed data used, are provided by the Togo National Meteorology Agency (Météo Togo). Please contact the authors if you are interested in this research data.

Author contributions. All authors developed the main research idea. LB, LEA and KDJ performed the analyses and evaluated the stress tests. LB wrote the manuscript with contributions and revisions from all authors.

Competing interests. The contact author has declared that neither they nor their co-authors have any competing interests.

Disclaimer. Publisher's note: Copernicus Publications remains neutral with regard to jurisdictional claims in published maps and institutional affiliations.

Special issue statement. This article is part of the special issue "Hydrology of Large River Basins of Africa". It is a result of the 4th International Conference on the "Hydrology of the Great Rivers of Africa", Cotonou, Benin, 13-20 November 2021.

Acknowledgements. All my gratitude to the International Association of Hydrological Sciences and local organizers who gave me financial support and took charge of my participation in 4th International Conference on the "Hydrology of the Great Rivers of Africa", Cotonou, Benin. We are also grateful to the anonymous reviewers whose thoughtful and constructive comments have improved the quality of the article.

Financial support. This research has been supported by the International Association of Hydrological Sciences (grant no. 13 SYSTA). 


\section{References}

Ague, A. I., Afouda, A., and Lanhoussi, F. : Etude Comparative D'un Modele Conceptuel Global (gr4j) Et D'un Modele Semi-distribue (geosfm) Sur Le Bassin Versant De L'oueme A Save (benin, Afrique De L'ouest), Le Journal de l'Eau et de l'Environnement (LJEE), 13, 2-8, 2014.

Allen, R., Pereira, L., Raes, D., and Smith, M.: Crop evapotranspiration guidelines for computing crop requirements, FAO Irrig. Drain. Report modeling and application, J. Hydrol., 285, 19-40, 1998.

Amoussou, E., Tramblay, Y., Totin, H. S. V., Mahé, G., and Camberlin, P.: . Dynamics and modelling of floods in the river basin of Mono in Nangbeto, Togo/Benin, Hydrolog. Sci. J., 59, 20602071, https://doi.org/10.1080/02626667.2013.871015, 2014.

Batablinlè, L., Lawin, E., and Agnide, C. M.: Africa Cordex Simulations Projection of Future Temperature, Precipitation, Frequency and Intensity Indices Over Mono Basin in West Africa, J. Earth Sci. Clim. Change, 9, 490, https://doi.org/10.4172/21577617.1000490, 2018.

Deutsches Klimarechenzentrum (DKRZ): Homepage, available at: https://esgf-data.dkrz.de/projects/esgf-dkrz/, last access: 3 August 2017.

Giertz, S. and Diekkrüger, B.: Analysis of the hydrological processes in a small headwater catchment in Benin (West Africa), Physics and Chemistry of the Earth, Parts A/B/C, 28, 1333-1341, https://doi.org/10.1016/j.pce.2003.09.009, 2003.

GNU Operating System: GNU General Public License, available at: http://www.gnu.org/copyleft/gpl.html, last access: August 2021.

Hargreaves, G. and Samini, Z.: Reference crop evapotranspiration from temperature, Appl. Eng. Agric., 1, 96-99, 1985.
Intergovernmental Panel on Climate Change (IPCC): Climate Change 2007: The Physical Science Basis. Contribution of Working Group I to the Fourth Assessment Report of the Intergovernmental Panel on Climate Change, available at: http://www.ipcc.ch/publications_and_data/ar4/syr/ en/contents.html (last access: 12 September 2019), 2007.

Jung, M., Reichstein, M., Ciais, P., Seneviratne, S., Sheffield, J., Goulden, M., Bonan, G., Cescatti, A., Chen, J., de Jeu, R., Dolman, A., Eugster, W., Gerten, D., Gianelle, D., Gobron, N., Heinke, J., Kimball, J., Law, B., Montagnani, L., Mu, Q., Mueller, B., Oleson, K., Papale, D., Richardson, A., and Roupsard, O.: Recent decline in the global land evapotranspiration trend due to limited moisture supply, Nature, 467 951-954, 2010.

Li, M., Chu, R., Shen, S., and Islam, A. R. M. T.: Quantifying Climatic Impact on Reference Evapotranspiration Trends in the Huai River Basin of Eastern China, Water, 10, 144, https://doi.org/10.3390/w10020144, 2018.

Liu, B., Ma, Z., Feng, J., and Wei, R.: The relationship between pan evaporation and actual evapotranspiration in Xinjiang since 1960, Acta Geogr. Sin., 63, 1131-1139, 2008.

Perrin, C., Michel, C., and Andréassian, V.: Does a large number of parameters enhance model performance? Comparative assessment of common catchment model structures on 429 catchments, J. Hydrol., 242, 275-301, 2001.

Terink, W., Immerzeel, W. W., and Droogers, P.: Climate change projections of precipitation and reference evapotranspiration for the Middle East and Northern Africa until 2050, Int. J. Climatol., 33, 3055-3072, 2013. 